\title{
Self-Reported Effectiveness and Physician Consultation Rate in Users of Over-the-Counter Histamine-2 Receptor Antagonists
}

\author{
Michael J. Shaw, M.D., F.A.C.G., A. Mark Fendrick, M.D., F.A.C.G., Robert L. Kane, M.D., \\ Susan A. Adlis, M.S., and Nicholas J. Talley, M.D., Ph.D., F.A.C.G. \\ Health Research Center, Park Nicollet Clinic, HealthSystem Minnesota, St. Louis Park, Minnesota; Clinical \\ Outcomes Research Center, Health Services Research Institute, School of Public Health, University of \\ Minnesota, Minneapolis, Minnesota; Division of General Internal Medicine, Department of Medicine, \\ University of Michigan Medical School, Ann Arbor, Michigan; and Department of Medicine, University of \\ Sydney, Penrith, Australia
}

OBJECTIVE: Decreased physician visits for dyspepsia were predicted with the histamine-2 receptor antagonists (H2RA) release to over-the-counter (OTC) status. The aim of this study was to examine the presentation frequency for dyspeptic complaints before and after the OTC release of the H2RA and the self-reported effectiveness of OTC H2RA.

METHODS: Two cross-sectional surveys were used in a community sample. The patients comprised a random age- and sex-stratified sample of 1600 ambulatory adults in 1993 and 1800 in 1997. Self-report, valid mail surveys gathered information on healthcare seeking and gastrointestinal symptoms in 1993 and 1997 and antisecretory use in 1997.

RESULTS: Presentation frequency for dyspepsia was $22 \%$ in 1993 versus $23.5 \%$ in 1997 . Only $16 \%$ of chronic users of the OTC H2RA obtained complete relief of symptomatic episodes. Use of an OTC H2RA was highly associated with presentation to a physician in the past year.

CONCLUSIONS: OTC H2RA infrequently provided the complete relief desired by patients. Presentation frequency to physicians for dyspeptic complaints did not change with availability of H2RA OTC. (Am J Gastroenterol 2001;96: 673-676. (C) 2001 by Am. Coll. of Gastroenterology)

\section{INTRODUCTION}

Most patients with complaints of upper gastrointestinal (GI) distress do not seek professional medical care, but opt for self-directed treatment. Community surveys in the United States and Europe have demonstrated that no more than $25 \%$ of persons with dyspeptic complaints including reflux symptoms consulted a physician in the previous year $(1,2)$. Dyspepsia sufferers will visit a physician, however, when despite self-directed treatment, pain becomes frequent, severe, long lasting, or anxiety provoking $(2,3)$. Approximately $2-4 \%$ of physician office visits annually have been reported to be due to symptoms related to dyspepsia or gastroesophageal reflux disease (GERD) (4).

Antacids have been the mainstay of self-directed dyspepsia treatment (3). The histamine-2 receptor antagonists (H2RA) have been established as safe and efficacious prescription treatment for acid-peptic disorders (5). Accordingly, they were considered excellent candidates for an over-the-counter (OTC) switch (6). Clinical and economic benefits were anticipated after release of H2RA to OTC status at half prescription strength in 1995. A decision analysis suggested that physician visits for dyspepsia would decrease by one million per year (7). Another decision analysis modeled costs and indicated that at least $60 \%$ of users need to obtain complete relief of symptomatic episodes for societal cost savings to occur (8). Published efficacy data are limited $(9,10)$. Overall, $70 \%$ of subjects who obtained some relief from antacids experienced complete relief of symptomatic episodes using H2RA in the OTC dose (10).

No data from unselected, community populations have been reported in the $5 \mathrm{yr}$ since OTC approval. Accordingly, we examined the rate of presentation to physicians for a dyspeptic complaint and patient reports of H2RA effectiveness in a randomly selected, ambulatory population.

\section{MATERIALS AND METHODS}

Community surveys of GI symptoms were performed $2 \mathrm{yr}$ before and $2 \mathrm{yr}$ after the OTC switch of H2RA. In September 1993, 800 men and 800 women aged 20-80 yr were randomly selected from the administrative databases of Park Nicollet Clinic (PNC) enrollees and Group Health. PNC is a 425-physician multispecialty group serving Minneapolis, MN, and surrounding suburbs. Group Health is a multispecialty staff model HMO serving the same area. Nearly half of PNC enrollees' health plans were administered by Group Health. Educational level of subjects was similar in both 
systems and all had pharmacy benefits. Those selected were mailed a 56-question survey including the valid and reliable Bowel Disease Questionnaire (BDQ) (11), and questions about the influence of abdominal pain on activities, physician visits in the past year, and history of peptic ulcer disease.

A similar survey was performed in August 1997. A total of 900 men and 900 women aged 20-80 yr were randomly selected from the computer database of PNC enrollees. Those selected were mailed a 98-question survey including a valid and reliable measure of GI tract symptoms-the Digestive Health Status Instrument (DHSI) (12), and the Rand Short Form-36, questions on healthcare seeking and antisecretory use. The DHSI was derived from the BDQ such that symptom items were the same except for minor scaling changes in the 1993 and 1997 surveys.

Presentation rates to a physician for a dyspeptic complaint and for reflux symptoms from the 1993 survey were compared with 1997 after the data were age and gender adjusted to 1990 State of Minnesota census data. A $\chi^{2}$ test statistic was used for the comparison.

For the variables: frequency of OTC H2RA use, dosage compliance, self-reported effectiveness, medication use, distributions, and rates were calculated. Means and standard deviations were calculated for age, race, and educational level.

The DHSI was used to identify those with dyspepsia and the reasons for OTC H2RA use. GERD was identified by questions inquiring about heartburn or acid regurgitation. Subjects with abdominal pain or discomfort centered in the upper abdomen of greater than 1-month duration were considered to have dyspepsia. The six Manning criteria were used to identify those with irritable bowel syndrome using a cut-off of two or more criteria (13).

Factors associated with physician consultation in the past year were examined using multivariable logistic regression analysis. The dependent variable was presentation to physician to discuss upper abdominal pain or heartburn in the past year. Demographic variables and factors significantly associated with presentation on bivariate analyses were incorporated into the model as independent variables. These included age, gender, educational level, use of OTC H2RAs, prior physician visits for these complaints, DHSI subscale scores, concern that symptoms were caused by a life-threatening illness, and SF-36 physical and mental component summaries.

The sponsor did not participate in study design, execution, or manuscript preparation.

\section{RESULTS}

Response rates and characteristics of respondents were very similar from the 1993 and 1997 surveys (data not shown); overall $70.6 \%$ in 1993 and $71.8 \%$ in 1997 returned the questionnaire. Respondents had a mean age of $52.6 \mathrm{yr}$ in 1993 and 51.8 yr in 1997, were predominantly white $(95.2 \%$
Table 1. Presentation to a Physician in the Preceding Year for Dyspepsia or Heartburn

\begin{tabular}{llc}
\hline & \multicolumn{2}{c}{ Mean \% With Condition $(\mathrm{CI})$} \\
\cline { 2 - 3 } & \multicolumn{1}{c}{1993} & 1997 \\
\hline Condition & & \\
Dyspepsia* & $22.0(17.4,25.2)$ & $23.5(18.5,27.8)$ \\
Heartburn $\dagger$ & $23.6(18.5,29.4)$ & $21.9(17.9,26.2)$ \\
\hline * Experienced the complaint at least once in the previous year. \\
$\begin{array}{l}\dagger \text { Experienced the complaint at least once per month in the previous year. } \\
\text { CI }=\text { confidence interval. }\end{array}$
\end{tabular}

in 1993 and $94.8 \%$ in 1997), female (56\% in 1993 and 55\% in 1997), and highly educated $(94.3 \%$ and $94.8 \%$ high school graduates, $72.9 \%$ and $73.7 \%$ postsecondary education in 1993 and 1997, respectively). Nonrespondents were younger (47.9 $\mathrm{yr}$ in 1993 and $48.3 \mathrm{yr}$ in 1997) and more likely to be male (64\% in 1993 and 63\% in 1997).

Prevalence of dyspepsia and heartburn was unchanged in 1993 and 1997. A total of $23.5 \%$ of respondents with dyspepsia reported presenting to a physician in the 1997 survey compared with $22.0 \%$ in the 1993 survey (Table 1). A total of $21.9 \%$ of heartburn sufferers consulted a physician in 1997 versus $23.5 \%$ in 1993 . These changes were not significant. With an alpha of 0.05 , and using a two-tailed test, the study sample size had a power of $79 \%$ to detect a $5 \%$ change and $99 \%$ to detect a $10 \%$ change.

Thirteen independent variables were entered into the logistic regression analysis. Five were significantly associated with presentation to physicians for evaluation of upper abdominal pain or heartburn (Table 2). This association was particularly strong for OTC use. The R-square of 0.28 and the c-statistic of 0.78 attest to the strength of the model (data not shown).

Only $14.9 \%$ of those using OTC medication chronically during the previous year achieved complete relief of symptoms (Fig. 1). An additional $27.6 \%$ reported marked, but incomplete relief. Of the 189 who used the OTC H2RA at least monthly, $78.3 \%$ used two or more antisecretory agents (Table 3$)$. A total of $10.6 \%(\mathrm{n}=20)$ received a prescription antisecretory agent (prescription H2RAs, proton pump inhibitors, or prokinetic agent). Over half used antacids $(\mathrm{n}=$ 99 or $52.3 \%$ )

A total of $6.7 \%$ of persons who used OTC medications at least monthly had symptoms limited only to the irritable bowel syndrome. Most regular OTC medication users experienced at least monthly reflux symptoms and upper ab-

Table 2. Factors Significantly Associated With Presentation to a Physician in the Past Year

\begin{tabular}{lc}
\hline \multicolumn{1}{c}{ Variable } & $p$ Value \\
\hline OTC use & $<0.0001$ \\
DHSI pain experience scale & 0.005 \\
Gender & 0.039 \\
Concern about fatal illness & 0.047 \\
DHSI reflux/ulcer scale & 0.048 \\
\hline
\end{tabular}

OTC $=$ over the counter; DHSI $=$ Digestive Health Status Instrument. 


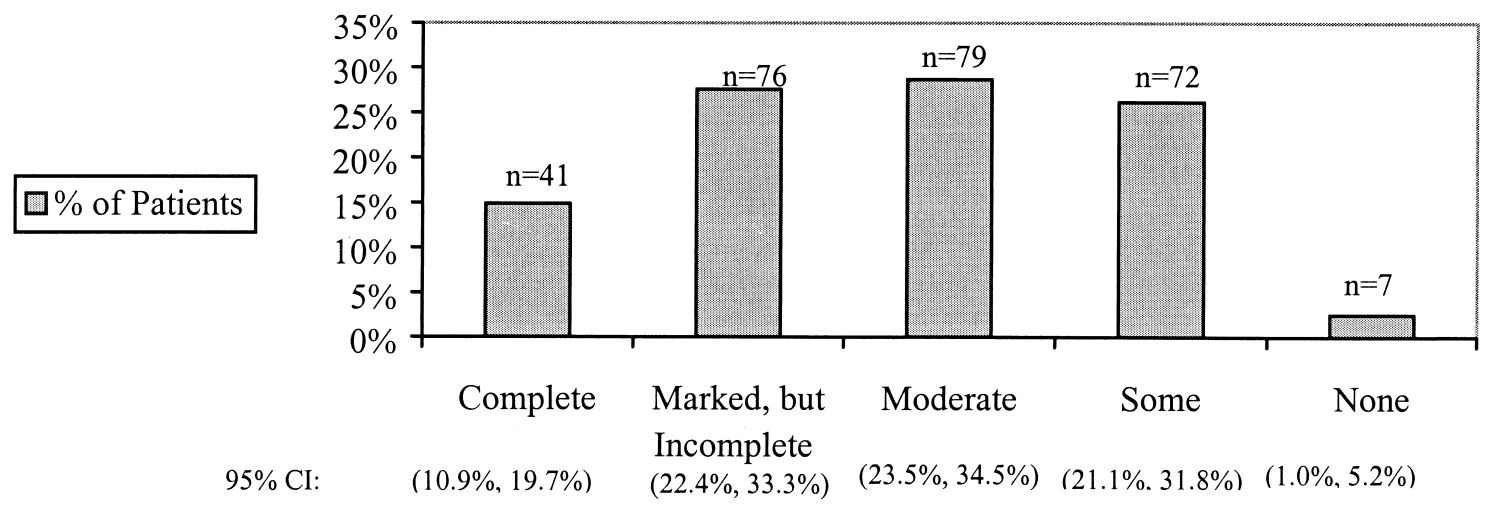

Figure 1. Treatment response in OTC H2RA users.

dominal pain/discomfort (75.8\%); the remainder took these medications for relief of upper abdominal pain/discomfort without reflux symptoms. A total of $86 \%$ of those who ever used OTC agents in the last year reported taking the medication in recommended doses. Only 7\% indicated they exceeded the recommended dose.

\section{DISCUSSION}

Scant empiric data are available to examine the clinical and economic impact of a switch to OTC status of a prescription medication. The need for these data are especially acute for the H2RAs as the decision to release these products to unregulated OTC status was made when significant uncertainty remained regarding optimal clinical management for dyspepsia. Morever, there were expectations that the availability of effective agents without the need for a doctor's prescription would decrease physician visits and direct medical expenditures for these common disorders (7).

The economic benefits of reduced physician visits suggested by a decision model did not occur despite the fact that this ambulatory population reported using these medications for approved indications in appropriate doses (7). Another decision model identified the threshold of complete symp-

Table 3. Over-the-Counter Medication Use for Dyspepsia/ Heartburn (1238 Respondents)

\begin{tabular}{llr}
\hline & \multicolumn{2}{c}{ Frequency of Use } \\
\cline { 2 - 3 } \multicolumn{1}{c}{ Assessment } & $\%(\mathrm{CI})$ & $(\mathrm{n})$ \\
\hline Use in previous year & & \\
Ever* & $22.0(20.1,24.8)$ & $(277)$ \\
Chronic $\dagger$ & $15.0(13.3,17.4)$ & $(189)$ \\
Chronically used medication & & \\
OTC H2RA & $15.3(13.3,17.4)$ & $(189)$ \\
Antacid & $12.6(10.8,14.6)$ & $(156)$ \\
Prescription H2RAs & $5.0(3.9,6.4)$ & $(62)$ \\
Proton pump inhibitor & $1.9(0.2,2.8)$ & $(23)$ \\
Promotility agent & $0.3(0.09,0.8)$ & $(4)$ \\
* At least once in the previous year. & & \\
$\quad \dagger$ At least once per month in the previous year. & \\
$\quad$ CI $=$ confidence interval; OTC $=$ over the counter; H2RA $=$ histamine-2 receptor \\
antagonist.
\end{tabular}

tom relief necessary to achieve reduced societal costs of care (8). This threshold was not reached in our population. The multivariable analysis suggested that if anything, the availability of OTC H2RAs led patients to seek consultation with physicians.

The approval of OTC therapy for candida vaginitis led to decreased physician visits and prescription medication use (14). The acute, self-limited aspect of vaginitis combined with effective OTC preparations account for these outcomes. Societal economic benefit is an appropriate expectation for OTC switches. Higher effectiveness than provided by half-prescription strength H2RA will be necessary to achieve this result for the dyspeptic disorders.

Our results lend partial support for releasing the H2RAs to OTC status on clinical grounds. Some of the safety concerns regarding inappropriate use and dosing seem unjustified because in our sample respondents reported use for approved indications and in recommended doses. Their common and regular use suggest that they provide symptomatic benefit.

We have highlighted key clinical and economic issues related to the OTC H2RA switch, but the reader should be mindful of some study limitations. Costs of care were not measured. Self-report data, especially when the time frame of observation extends for a year, may possess some inaccuracy (15). The self-report effectiveness data were derived from a homogeneous population where antisecretory treatment was heterogeneous and not directly observed. Nonetheless, these data derived from a large community-based population are one of the few studies assessing the effectiveness of an OTC transition. In addition, the prevalence and consultation rates are similar to what has been reported elsewhere (2).

In summary, an ambulatory population reported using the OTC H2RAs appropriately and as commonly as antacids. Expectations for the effectiveness of these medications do not seem to have been met, however. As sole treatment, complete relief was infrequently provided. The frequency of physician visits for dyspeptic complaints seem unaffected by the use of these medications. Physician visits are only 
one component of total disease-related costs; thus, the overall economic impact of the OTC H2RA transition is unknown.

\section{ACKNOWLEDGMENT}

This study was supported in part by an unrestricted grant from AstraZeneca, Wayne, Pennsylvania.

Reprint requests and correspondence: Michael J. Shaw, 3800 Park Nicollet Boulevard, St. Louis Park, MN 55416.

Received July 27, 2000; accepted Nov. 1, 2000.

\section{REFERENCES}

1. Jones RH, Lydeard SE, Hobbs FDR, et al. Dyspepsia in England and Scotland. Gut 1990;31:401-5.

2. Talley NJ, Zinsmeister AR, Schleck AD, et al. Dyspepsia and dyspepsia subgroups: A population-based study. Gastroenterol 1992;102:1259-67.

3. Lydeard S, Jones R. Factors affecting the decision to consult with dyspepsia: Comparison of consulters and non-consulters. J R Coll Gen Pract 1989;39:495-8.

4. Adami HO, Agenas I, Gustavsson S, et al. The clinical diagnosis of "gastritis" aspects of demographic epidemiology and health care consumption based on a nationwide sample survey. Scand J Gastroenterol 1984;19:216-9.

5. Feldman M. Pros and cons of over-the-counter availability of histamine $_{2}$-receptor antagonists. Arch Intern Med 1993;153: 2415-24.
6. Spiro HM. Paternalism by prescription? Drug Ther 1992;22: 135-7.

7. Oster G, Huse DM, Delea TE, et al. The risks and benefits of an Rx-to-OTC switch: The case of over-the-counter $\mathrm{H}_{2}$-blockers. Medical Care 1990;9:834-52.

8. Kalish SC, Bohn BL, Avorn J. Policy analysis of the conversion of histamine ${ }_{2}$ antagonists to over-the-counter use. Medical Care 1997;1:32-48.

9. Gottlieb S, Decktor DL, Eckert JM, et al. Efficacy and tolerability of famotidine in preventing heartburn and related symptoms of upper gastrointestinal discomfort. Am J Ther 1995;2:314-9.

10. Simon TJ, Berlin RG, Gardner AH, et al. Self-directed treatment of intermittent heartburn: A randomized, multicenter, double-blind, placebo-controlled evaluation of antacid and low doses of an $\mathrm{H}_{2}$-receptor antagonist (famotidine). Am J Ther 1995;2:304-13.

11. Talley NJ, Phillips SF, Melton LJ III, et al. A patient questionnaire to identify bowel disease. Ann Intern Med 1989;11: 671-4.

12. Shaw MJ, Talley NJ, Adlis SA, et al. Development of a digestive health status instrument: Tests of scaling assumptions, structure and reliability in a primary care population. Aliment Pharmacol Ther 1998;12:1067-78.

13. Manning AP, Thompson WG, Heaton KW, et al. Towards a positive diagnosis of irritable bowel syndrome. Br Med J 1978;2:653-4.

14. Gurwitz JH, McLaughlin TJ, Fish LS. The effect of an Rxto-OTC switch on medication prescribing patterns and utilization of physician services: The case of vaginal antifungal products. Health Serv Res 1995;5:672-85.

15. Stewart AL, Hays RD, Ware JE Jr. Methods of constructing health measures. In: Stewart AL, Ware JE Jr, eds. Measuring functioning and well-being. Durham, NC: Duke University Press, 1992:67-85. 